\title{
Sorafenib therapy following resection prolongs disease-free survival in patients with advanced hepatocellular carcinoma at a high risk of recurrence
}

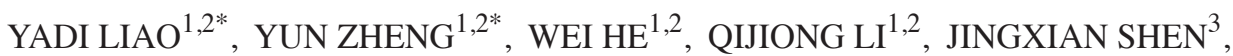 \\ JIAN HONG ${ }^{1,2}$, RUHAI ZOU ${ }^{4}$, JILIANG QIU ${ }^{1,2}$, BINKUI LI ${ }^{1,2}$ and YUNFEI YUAN ${ }^{1,2}$
}

\begin{abstract}
${ }^{1}$ State Key Laboratory of Oncology in South China, Collaborative Innovation Center for Cancer Medicine, Sun Yat-Sen University Cancer Center; Departments of ${ }^{2}$ Hepatobiliary Oncology, ${ }^{3}$ Medical Imaging and Interventional Center and ${ }^{4}$ Ultrasound, Sun Yat-Sen University Cancer Center, Guangzhou, Guangdong 510060, P.R. China
\end{abstract}

Received February 14, 2015; Accepted May 13, 2016

DOI: $10.3892 / 01.2016 .5525$

\begin{abstract}
Sorafenib is the standard systemic treatment for patients with advanced hepatocellular carcinoma (HCC); however, its therapeutic value in patients with HCC following resection remains controversial. The current retrospective study was undertaken to assess the effects of sorafenib treatment following surgical resection in patients with advanced HCC disease who were at a high risk for recurrence. Between July 2010 and July 2013, a consecutive cohort of 42 patients with advanced $\mathrm{HCC}$ and at a high risk of recurrence (i.e., those with portal vein tumor thrombosis, adjacent organ involvement or tumor rupture) who underwent resection were analyzed. The patients were categorized into the sorafenib group $(n=14)$ or the best supportive care (BSC) group $(\mathrm{n}=28)$. Although the histological grade, Barcelona Clinic Liver Cancer Stage, tumor size, nodule number and proportion of patients with high serum $\alpha$-fetoprotein levels were comparable between the sorafenib and BSC groups, those receiving sorafenib following resection had significantly longer disease-free survival (DFS) of 5.2 months
\end{abstract}

Correspondence to: Dr Binkui Li or Dr Yunfei Yuan, Department of Hepatobiliary Oncology, Sun Yat-Sen University Cancer Center, 651 Dongfeng Road East, Guangzhou, Guangdong 510060, P.R. China

E-mail: libinkui@mail.sysu.edu.cn

E-mail: yuanyf@mail.sysu.edu.cn

*Contributed equally

Abbreviations: AFP, $\alpha$-fetoprotein; BSC, best supportive care; CI, confidence interval; DFS, disease-free survival; HCC, hepatocellular carcinoma; PEI, percutaneous ethanol injection; PVTT, portal vein tumor thrombus; SHARP, sorafenib HCC assessment randomized protocol; TACE, transcatheter arterial chemoembolization

Key words: best supportive care, disease-free survival, hepatocellular carcinoma, resection, sorafenib
[95\% confidence interval (CI), 1.2-9.2 months] compared with the BSC group [1.8 months (95\% CI, 0.6-3.0 months)]. No differences in overall survival were noted between the groups. Furthermore, no drug-related adverse events resulted in discontinuation of sorafenib therapy. Univariate log-rank analysis revealed that sorafenib treatment $(\mathrm{P}=0.002)$ and treatment prior to resection $(\mathrm{P}=0.012)$ were significantly associated with longer DFS; however, sorafenib therapy $(\mathrm{P}=0.027)$ and tumor size $(\mathrm{P}=0.028)$ were associated with longer $\mathrm{DFS}$ by multivariate analysis. Furthermore, sorafenib was well-tolerated and improved DFS in patients with advanced HCC who underwent hepatic resection. Thus, tumor resection followed by sorafenib therapy may represent an effective therapeutic strategy for patients with advanced HCC. This possibility should be confirmed in larger, multicenter studies.

\section{Introduction}

Hepatocellular carcinoma is the fifth most prevalent type of cancer (1) and the third most common cause of cancer-related mortality worldwide (2). There are $>700,000$ new cases of HCC diagnosed each year worldwide (2), and the mortality rate is similar to the incidence rate due to high levels of intrahepatic recurrence and distant metastasis, and the lack of effective treatments (2). Despite advances in various treatment strategies, such as resection, transplantation, ablation, chemoembolization and targeted therapy with sorafenib, the prognosis of patients with HCC remains poor due to disease recurrence $(1,3)$. In addition to transplantation, hepatic resection is considered the most effective treatment strategy, with a 5 -year survival rate of $60-80 \%$ for selected patients $(4,5)$.

The selection criteria for resection are as follows: i) Patients with solitary tumors and very well-preserved liver function, as normal bilirubin with either hepatic venous pressure gradient $\leq 10 \mathrm{mmHg}$ or platelet count $\geq 100,000$ cells; and ii) patients with multifocal tumors meeting the Milan criteria ( $\leq 3$ nodules of $\leq 3 \mathrm{~cm}$ ) or with mild portal hypertension who are not suitable for liver transplantation require prospective comparisons with loco-regional treatments. However, liver transplantation is considered to be the first line treatment option for patients 
with single tumors of $<5 \mathrm{~cm}$ or with $\leq 3$ nodules of $\leq 3 \mathrm{~cm}$ (Milan criteria) which are not suitable for resection $(1,2)$.

No effective therapy to reduce the risk of HCC recurrence is currently available (6), and systemic chemotherapy, hepatic-artery chemotherapy and chemoembolization have little effect $(7,8)$. Other treatments, such as immunotherapy and interferon therapy, may improve overall survival and recurrence-free survival (9-12). However, more studies are required before they can be recommended a part of the routine clinical practice.

$\mathrm{HCC}$ is further complicated by the incidence of portal vein tumor thrombosis (PVTT), tumors involving adjacent organs or those with tumor rupture. The prognosis for patients with HCC complicated by PVTT is extremely poor, with a median survival of only 2-4 months (13-17) for those receiving surgical resection, portal vein stent, transcatheter arterial chemoembolization (TACE), radiotherapy, ${ }^{125}$ I seed implantation, percutaneous ethanol injection (PEI) or laser ablation (18).

Sorafenib is a multikinase inhibitor that targets the serine/threonine kinases, Raf-1 and B-Raf; the mitogen-activated protein kinases, mitogen-activated protein kinase kinase and extracellular signal-regulated kinase; and the receptor tyrosine kinase activity of vascular endothelial growth factor receptors 1-3; and platelet-derived growth factor receptor- $\beta$ (19-22). In the phase III Sorafenib HCC Assessment Randomized Protocol (SHARP) (23) and Asian-Pacific (24) studies, sorafenib improved the overall survival of patients with advanced, unresectable HCC by 3 months. Thus, Western guidelines, including the American Association for the Study of Liver Diseases and the European Association for the Study of the Liver $(3,4)$, recommend sorafenib as the standard systemic treatment for advanced HCC. By contrast, sorafenib is not widely available in Asian-Pacific countries; instead, surgical resection is a more common treatment for patients with advanced HCC. In a small pilot study that included 31 patients with advanced $\mathrm{HCC}$, the recurrence rate was decreased in patients receiving sorafenib following resection (25). As the outcomes of patients with advanced HCC remains poor with sorafenib monotherapy, the present study aimed to determine if the survival of HCC patients with a high risk of recurrence (i.e., those with PVTT, tumors involving adjacent organs or those with tumor rupture) who underwent resection could be prolonged. The association between clinicopathological characteristics and disease-free survival (DFS) was analyzed by univariate and multivariate analyses. Sorafenib therapy following resection may represent a novel approach for treating patients with advanced $\mathrm{HCC}$ that are at a high risk for tumor recurrence.

\section{Patients and methods}

Patients. A total of 42 patients with HCC that were at high risk of disease recurrence and who underwent hepatic resection between July 2010 and July 2013 at the Sun Yat-Sen University Cancer Center (Guangzhou, China) were included in the present study. Demographic data such as Eastern Cooperative Oncology Group performance status (ECOG PS) score, Barcelona Clinic Liver Cancer Stage (BCLC) stage and Child-Pugh class were determined prior to resection. The scores were calculated on the basis of common criteria as described in previous studies (26-28). Histological grade was classified following resection according to the criteria of the World Health Organization Classification of Tumors (2000) (29). All samples were obtained prior to surgery to determine serology, $\alpha$-fetoprotein (AFP), alanine aminotransferase (ALT), aspartate aminotransferase (AST), alkaline phosphatase (ALP), albumin and bilirubin levels, and prothrombin time. The normal ranges are as follows: AFP, 0-25 ng/ml; ALT, 0-40 U/1; AST, 0-45 U/L; ALP, 30-110 U/1; albumin, 35-55 g/l; bilirubin, 5.0-20.5 $\mu \mathrm{mol} / 1$; and prothrombin time, $10.5-13.5 \mathrm{sec}$. The diagnosis of HCC was confirmed by pathological examination. All diagnoses were formulated according to the criteria for terminology established by the International Working Party (30). Tumor differentiation was based on the criteria of the World Health Organization Classification of Tumors (2000) (29). Tumor stage was defined according to the 2010 American Joint Committee on Cancer/International Union Against Cancer tumor-node-metastasis classification system (31). Patients were defined as being at a high risk of recurrence if they had one of the following intraoperative findings: i) Tumors involving a major branch of the portal or hepatic vein (i.e., PVTT); ii) tumors with direct invasion of adjacent organs; and iii) tumor ruptures prior to or during resection (Table I). Patients were excluded if they had one of the following: i) A history of molecularly targeted therapy or systemic chemotherapy following resection; ii) severe coagulation disorders (prothrombin activity of $<40 \%$ or platelet count of $<4,000$ cells $/ \mu 1$ ); or iii) hepatic decompensation, including ascites, esophageal or gastric variceal bleeding, and hepatic encephalopathy. The present study was approved by the institutional review board of the Sun Yat-Sen University Cancer Center, who confirmed that patient consent was not required for the present retrospective study.

Tumor resection. The extent of resection was performed according to the standard of practice, as described by Luo et al (32). For those with PVTT, the liver tumor was completely removed such that the surgical margin was negative and the tumor thrombus was removed after opening the portal vein. For those with tumor rupture, the liver tumor was completely removed such that the surgical margin was negative. For those tumors involving adjacent organs, the liver tumor was completely removed such that the surgical margin was negative and the diaphragm or the omentum was partially removed.

Sorafenib therapy, toxicity evaluation and treatment response. Patients received either sorafenib treatment $(n=14)$ or best supportive care (BSC; $n=28$ ) following resection. According to the American Association for the Study of Liver Diseases and the European Association for the Study of the Liver guidelines $(1,5)$, no effective adjuvant therapy able to reduce recurrence rates following resection is available at present. Thus, the best supportive care in Sun Yat-Sen University Cancer Center included nutrition education, liver protection, pain management and psychotherapy. For patients with a high risk of recurrence, sorafenib was routinely recommended by the treating physician. Upon recommendation, patients were asked to decide whether to receive the optional sorafenib treatment. Sorafenib therapy was initiated 7 days after surgery 
Table I. Summary of the proportion of patients according to the risk factor selection criteria.

\begin{tabular}{lcccr}
\hline Risk factor & $\begin{array}{c}\text { Total patients } \\
(\mathrm{n}=42)\end{array}$ & $\begin{array}{c}\text { Sorafenib group } \\
(\mathrm{n}=14)\end{array}$ & $\begin{array}{c}\text { BSC group } \\
(\mathrm{n}=28)\end{array}$ & P-value \\
\hline PVTT & $31(73.8)$ & $11(78.6)$ & $20(71.4)$ & 0.723 \\
Tumor involving adjacent organs & $6(14.3)$ & $2(14.3)$ & $4(14.3)$ & 1.000 \\
Tumor rupture & $5(11.9)$ & $1(7.1)$ & $4(14.3)$ & 0.650 \\
\hline
\end{tabular}

Data are presented as n (\%). Differences between groups were compared using the Fisher's exact test. There was no significant difference between the groups. BSC, best supportive care; PVTT, portal vein tumor thrombus.

with an initial dose of $400 \mathrm{mg}$ sorafenib. Patients in this group received continuous oral treatment with $400 \mathrm{mg}$ sorafenib (Bayer AG, Leverkusen, Germany) twice daily. The dose was reduced in the event of unacceptable drug-related side-effects, including hand-foot skin reaction, diarrhea, rash and hypertension. Sorafenib toxicity was evaluated according to the National Cancer Institute's Common Terminology Criteria for Adverse Events, version 3.0 (33). Tumor response and recurrence were evaluated every 4-8 weeks, according to Response Evaluation Criteria in Solid Tumors (34), by performing computed tomography or magnetic resonance imaging scans of the liver. DFS was defined as the time from resection to the date of tumor recurrence or the patient's most recent follow-up examination.

Statistical analysis. Baseline characteristics are expressed as $\mathrm{n}(\%)$ for categorical data and mean \pm standard deviation (SD) for continuous data by group. Differences between groups were compared using Pearson's $\chi^{2}$ or Fisher's exact tests for categorical data; two-sample t-tests were used for continuous data. Data normal distribution was determined by one-sample Kolmogorov-Smirnov test with $\mathrm{P}<0.05$. For continuous data that did not follow normal distribution, data are expressed as median (range) and the Mann-Whitney $U$ test was used to compare between groups. DFS data are presented using Kaplan-Meier survival curves by group and compared using log-rank tests. Univariate and multivariate Cox regression analyses were performed to identify the prognostic factors associated with DFS. For multivariate analysis, variable selection was performed using the backward elimination method with $\mathrm{P}<0.1$ set as the cutoff level. According to previous studies (35-38), factors associated with early recurrence were non-anatomical resection, microscopic vascular invasion and serum AFP level, while those contributing to late-phase recurrence were hepatitis activity, multiple tumors and histological grade. Thus, considering clinical significance and the results of previous studies (6-9), 8 factors were selected as potential confounders in the present study. The 8 factors were as follows: Sorafenib (yes vs. no), hepatitis serology (hepatitis B surface antigen-positive vs. other), histological grade (poor vs. well-moderate), tumor size ( $\geq 10$ vs. $<10 \mathrm{~cm}$ ), tumor nodules (multiple versus single), AFP ( $\geq 400 \mathrm{vs.}<400 \mathrm{ng} / \mathrm{ml}$ ), previous treatment (yes vs. no) and anti-virus treatment (yes vs. no). Results are presented as hazard ratios (HRs) with 95\% confidence intervals $(95 \% \mathrm{CI})$. All statistical assessments were two-tailed and $\mathrm{P}<0.05$ was considered to indicate a statistically significant difference. All statistical analyses were performed with SPSS statistical software for Windows (version 22; IBM SPSS, Chicago, IL, USA).

\section{Results}

Patient characteristics. Between July 2010 and July 2013, 42 consecutive HCC patients who underwent resection and were diagnosed as having a high risk of disease recurrence were enrolled in the present study, including 37 male and 5 female patients, with a mean age of 48.1 years (range, 28-69 years). Among the enrolled patients, 14 (33.3\%) received postoperative sorafenib therapy (sorafenib group) for a median duration of 14.3 months (range, 2.6-24.2 months) and the other 28 received BSC. As indicated in Table I, the proportion of patients with each high-risk factor was not significantly different between the two postoperative groups.

The demographic data of all of the enrolled patients are included in Table II. The majority of patients (97.6\%) had an ECOG PS score of 0-1 and 90.5\% were hepatitis B virus (HBV)-positive. There was no significant difference in the proportion of patients receiving anti-viral treatment between the sorafenib and BSC groups $(\mathrm{P}=0.261)$. In addition, all patients were classified as Child-Pugh class A (Child-Pugh score 5-6). No differences in the histological grade or BCLC stage were noted between the groups $(\mathrm{P}=0.326$ and $\mathrm{P}=1.000$, respectively). Tumor size, number of nodules and proportion of patients with high serum AFP levels $(\geq 400 \mathrm{ng} / \mathrm{ml}$ ) were also similar between the two groups $(\mathrm{P} \geq 0.259)$. However, a significantly higher proportion of patients in the sorafenib group received previous treatment compared with the BSC group $(\mathrm{P}=0.003)$. Furthermore, the sorafenib group had higher baseline albumin levels $(42.5 \pm 4.3$ vs. $39.4 \pm 3.4 \mathrm{~g} / \mathrm{l}$, $\mathrm{P}=0.016)$ and lower median baseline levels of ALP [75.1 U/1 (range, 44.4-185.5 U/1) vs. $112.9 \mathrm{U} / 1$ (range, 55.7-197.2 U/1); $\mathrm{P}=0.007]$ compared with the BSC group (Table II). Sorafenib was well-tolerated in all patients following hepatic resection, as there were no drug-related adverse events that led to discontinuity.

DFS analysis. Follow-up was performed until May 8, 2014. The median follow-up time was 13.6 months (range, 1.5-40.1 months). Of the total cohort, 9 patients ( 2 in the sorafenib group and 7 in the BSC group) succumbed to the disease and 38 patients (11 in the sorafenib group and 27 in the BSC group) developed recurrence during the follow-up period. 
Table II. Demographic data of the patients by group.

\begin{tabular}{|c|c|c|c|c|}
\hline Patient characteristic & $\begin{array}{l}\text { All patients } \\
\quad(n=42)\end{array}$ & $\begin{array}{l}\text { Sorafenib group } \\
\qquad(\mathrm{n}=14)\end{array}$ & $\begin{array}{l}\text { BSC group } \\
\quad(n=28)\end{array}$ & P-value \\
\hline Age, years & $48.1 \pm 10.8$ & $47.4 \pm 10.6$ & $48.4 \pm 11.0$ & 0.788 \\
\hline Gender & & & & 0.313 \\
\hline Male & $37(88.1)$ & $11(78.6)$ & $26(92.9)$ & \\
\hline Female & $5(11.9)$ & $3(21.4)$ & $2(7.1)$ & \\
\hline ECOG PS & & & & 1.000 \\
\hline $0-1$ & $41(97.6)$ & $14(100.0)$ & $27(96.4)$ & \\
\hline 2 & $1(2.4)$ & $0(0.0)$ & $1(3.6)$ & \\
\hline Hepatitis serology & & & & 0.100 \\
\hline HBsAg-positive & $38(90.5)$ & $11(78.6)$ & $27(96.4)$ & \\
\hline HBsAg-negative & $4(9.5)$ & $3(21.4)$ & $1(3.6)$ & \\
\hline Child-Pugh score & & & & 1.000 \\
\hline 5 & $38(90.5)$ & $13(92.9)$ & $25(89.3)$ & \\
\hline 6 & $4(9.5)$ & $1(7.1)$ & $3(10.7)$ & \\
\hline Histological grade & & & & 0.326 \\
\hline Well/moderate & $21(50.0)$ & $9(64.3)$ & $12(42.9)$ & \\
\hline Poor & $21(50.0)$ & $5(35.7)$ & $16(57.1)$ & \\
\hline BCLC stage & & & & 1.000 \\
\hline A & $4(9.5)$ & $1(7.1)$ & $3(10.7)$ & \\
\hline $\mathrm{B}$ & $1(2.4)$ & $0(0.0)$ & $1(3.6)$ & \\
\hline $\mathrm{C}$ & $37(88.1)$ & $13(92.9)$ & $24(85.7)$ & \\
\hline Tumor size, cm & & & & 0.738 \\
\hline$<10$ & $28(66.7)$ & $10(71.4)$ & $18(64.3)$ & \\
\hline$\geq 10$ & $14(33.3)$ & $4(28.6)$ & $10(35.7)$ & \\
\hline Tumor nodules & & & & 0.259 \\
\hline Single & $32(76.2)$ & $9(64.3)$ & $23(82.1)$ & \\
\hline Multiple & $10(23.8)$ & $5(35.7)$ & $5(17.9)$ & \\
\hline AFP, ng/ml & & & & 1.000 \\
\hline$<400$ & $20(47.6)$ & $7(50.0)$ & $13(46.4)$ & \\
\hline$\geq 400$ & $22(52.4)$ & $7(50.0)$ & $15(53.6)$ & \\
\hline Previous treatment & & & & $0.003^{\mathrm{a}}$ \\
\hline Yes & $7(16.7)$ & $6(42.9)$ & $1(3.6)$ & \\
\hline No & $35(83.3)$ & $8(57.1)$ & $27(96.4)$ & \\
\hline Anti-virus treatment & & & & 0.261 \\
\hline Yes & $16(38.1)$ & $7(50.0)$ & $9(32.1)$ & \\
\hline No & $26(61.9)$ & $7(50.0)$ & $19(67.9)$ & \\
\hline \multicolumn{5}{|c|}{ Baseline liver function, U/l } \\
\hline ALT & $42.7(14.8-153.6)$ & $43.4(14.8-120.5)$ & $42.5(18.2-153.6)$ & 0.644 \\
\hline AST & $44.3(18.6-412.3)$ & $46.5(19.7-412.3)$ & $42.4(18.6-295.7)$ & 0.722 \\
\hline ALP & $101.9(44.4-197.2)$ & $75.1(44.4-185.5)$ & $112.9(55.7-197.2)$ & $0.007^{\mathrm{a}}$ \\
\hline Albumin, g/l & $40.4 \pm 4.0$ & $42.5 \pm 4.3$ & $39.4 \pm 3.4$ & $0.016^{\mathrm{a}}$ \\
\hline Total bilirubin, $\mu \mathrm{mol} / 1$ & $15.6 \pm 6.2$ & $16.2 \pm 4.6$ & $15.2 \pm 6.9$ & 0.622 \\
\hline Prothrombin time, sec & $11.9(10.6-16.4)$ & $11.8(10.6-16.4)$ & $12(10.9-15.5)$ & 0.390 \\
\hline INR & $1.07(0.94-1.41)$ & $1.1(0.94-1.41)$ & $1.1(0.96-1.34)$ & 0.334 \\
\hline
\end{tabular}

Categorical data are expressed as n (\%). Continuous data are expressed as mean \pm standard deviation or median (range) by group. Differences between groups were compared using the Pearson $\chi^{2}$ test or Fisher's exact test for categorical data and two-sample t-tests for continuous data. For continuous data that did not follow normal distribution, the Mann-Whitney U test was used. Previous treatment means TACE and radiation therapy (i.e., treatments other than sorafenib). ${ }^{\mathrm{a}} \mathrm{P}<0.05$ indicates significant difference between groups. BSC, best supportive care; ECOG, Eastern Cooperative Oncology Group Performance Status; HBsAg, hepatitis B virus surface antigen; BCLC, Barcelona Clinic Liver Cancer Stage; AFP, $\alpha$-fetoprotein; ALT, alanine aminotransferase; AST, aspartate aminotransferase; ALP, alkaline phosphatase; INR, international normalized ratio. 


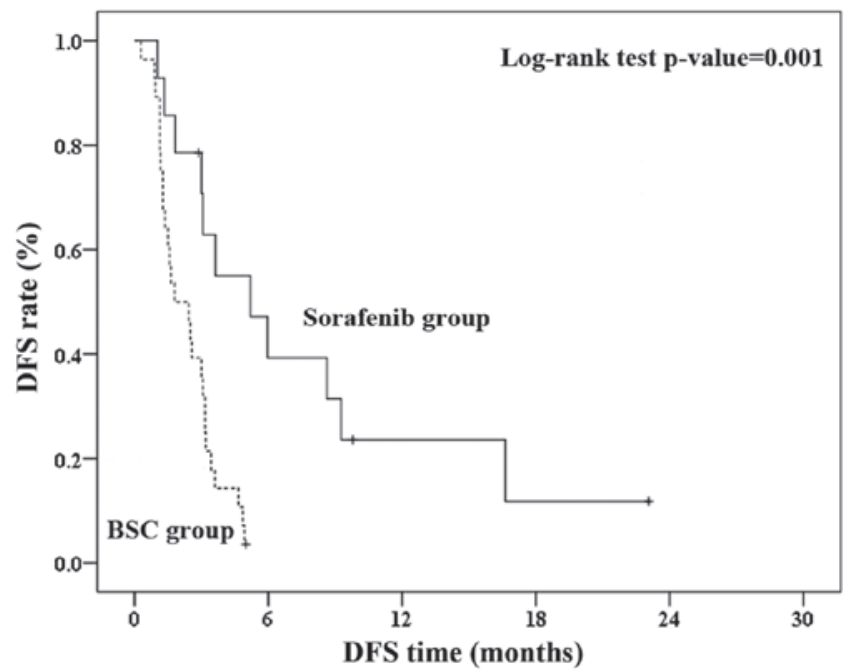

Figure 1. Kaplan-Meier curves of DFS rate by postoperative treatment. DFS time was significantly different between the sorafenib and BSC groups (log-rank test, $\mathrm{P}=0.001$ ). DFS, disease-free survival; BSC, best supportive care.

The mean overall survival time was 29.1 months (range, 1.5-40.1 months) and was comparable between the two groups $(\mathrm{P}=0.405)$. The overall median DFS time was 3.2 months (range, 0.3-16.6 months) and log-rank analysis revealed that patients in the sorafenib group had improved DFS of 5.2 months (95\% CI, 1.2-9.2 months) compared with those in the BSC group [1.8 months (95\% CI, 0.6-3.0 months); $\mathrm{P}=0.001$; Fig. 1]. Furthermore, patients that had received previous treatment (TACE and radiation therapy) prior to resection had longer DFS of 9.2 months (95\% CI, 0-23.7 months) compared with those that had not [2.5 months (95\% CI, 1.2-3.9 months); $\mathrm{P}=0.006$; Fig. 2].

Factors associated with DFS. Univariate and multivariate Cox regression analysis were performed to identify the factors associated with DFS. As indicated in Table III, there was no significant univariate association between DFS time and hepatitis serology, AFP level, tumor size, extent of tumor nodules, histological grade, Child-Pugh score or anti-virus treatment. However, sorafenib therapy (HR, 0.243, 95\% CI, 0.098-0.599; $\mathrm{P}=0.002)$ and previous treatment prior to resection (HR, 0.204, 95\% CI, 0.059-0.703; $\mathrm{P}=0.012$ ) were associated with a decreased recurrence rate upon univariate analysis. Furthermore, multivariate Cox regression analysis revealed that sorafenib treatment (HR, 0.328; 95\% CI, 0.122-0.880; $\mathrm{P}=0.027)$ and tumor size (HR, 0.449; 95\% CI, 0.220-0.917; $\mathrm{P}=0.028$ ) were significantly associated with DFS (Table III).

\section{Discussion}

Since the SHARP trial in 2007 (15), sorafenib has become the standard treatment for patients with advanced, unresectable HCC in the majority of countries worldwide, prolonging survival in these patients by $\sim 3$ months $(23,24)$. However, surgical resection is also an acceptable treatment for patients with advanced HCC in Asian-Pacific countries, as sorafenib is often not readily available. Long-term survivors with advanced $\mathrm{HCC}$ receiving sorafenib commonly require

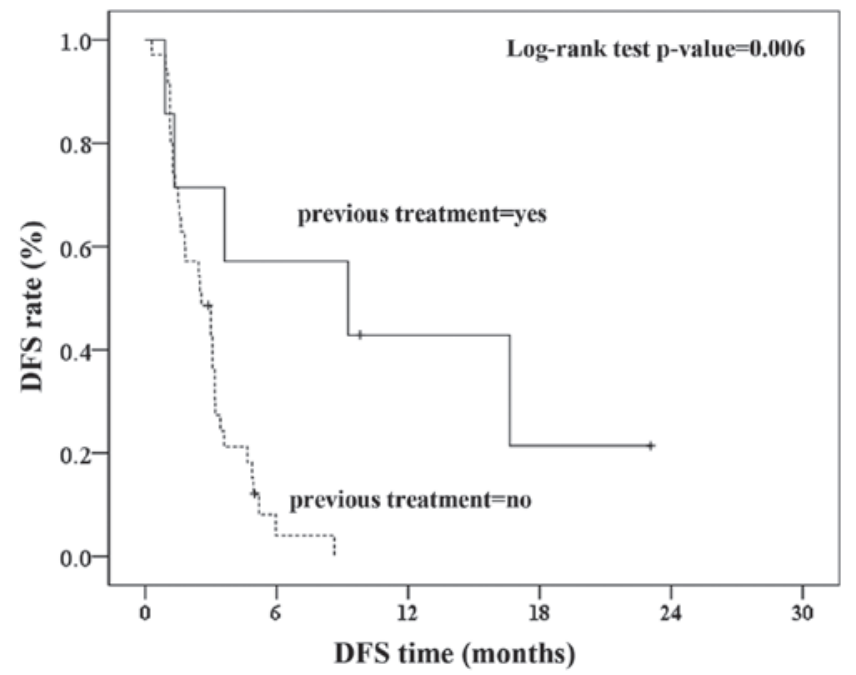

Figure 2. Kaplan-Meier curves of DFS rate for patients with and without previous treatment prior to resection. DFS time was significantly different between the two groups (log-rank test, $\mathrm{P}=0.006$ ). DFS, disease-free survival.

multimodal therapies, including hepatic resection following successful sorafenib treatment, salvage therapies in the event of progressive disease, and effective post-sorafenib treatment modalities (39). Thus, the current retrospective study was undertaken to assess the therapeutic value of administering sorafenib treatment following surgical resection in patients with advanced HCC disease that were at a high risk of recurrence (i.e., those with PVTT, adjacent organ involvement or tumor rupture). Although the histological grade, BCLC stage, tumor size, nodule number and proportion of patients with high serum AFP levels were comparable between the sorafenib and BSC groups, those receiving sorafenib following resection exhibited significantly improved DFS. Although a greater proportion of patients in the sorafenib group received treatment prior to resection, multivariate analysis indicated that sorafenib and tumor size were the only variables that were associated with DFS. In univariate analysis, the error from the confounders will be reflected in the random error, which will cause the denominator to appear greater than its actual value, resulting in reduced significance. Thus, if $>1$ factors affect the observation value, multivariate analysis should be applied.

The overall median DFS in the current study was 3.2 months, which is comparable with previous studies $(40,41)$. Dollinger et al observed that the time to progression of advanced HCC was 5.3 and 2.9 months for patients treated with thymostimulin and placebo, respectively (41). Nagano et al noticed that the overall median progression-free survival (PFS) of advanced HCC was 2.0 months (40). In addition, the association between sorafenib therapy and longer DFS is largely concordant with previous studies in patients with HCC $(25,42-52)$. In a pilot study by Wang et al (25) that included 31 patients at a high risk of recurrence, sorafenib therapy following hepatic resection significantly improved the time to recurrence as well as the recurrence rate. Furthermore, univariate analysis revealed that sorafenib following resection was independently associated with recurrence-free survival (25). In a different study, a complete response was observed in a single patient with hepatitis $\mathrm{C}$ virus-mediated cirrhosis and recurrent HCC with PVTT following treatment 
Table III. Univariate and multivariate Cox regression analysis of clinical factors associated with DFS in patients with hepatocellular cancer $(n=42)$.

\begin{tabular}{|c|c|c|c|c|c|}
\hline \multirow[b]{2}{*}{ Clinical factor } & \multirow[b]{2}{*}{ Median DFS (95\% CI) } & \multicolumn{2}{|c|}{ Univariate analysis } & \multicolumn{2}{|c|}{ Multivariate analysis } \\
\hline & & $\operatorname{HR}(95 \% \mathrm{CI})$ & P-value & $\operatorname{HR}(95 \% \mathrm{CI})$ & P-value \\
\hline \multicolumn{6}{|l|}{ Sorafenib } \\
\hline Yes & $5.2(1.2-9.2)$ & $0.243(0.098-0.599)$ & $0.002^{\mathrm{b}}$ & $0.328(0.122-0.880)$ & $0.027^{\mathrm{b}}$ \\
\hline No & $1.8(0.6-3.0)$ & Reference & & Reference & \\
\hline Age, years & $3.0(2.3-3.6)$ & $0.980(0.947-1.013)$ & 0.232 & - & \\
\hline \multicolumn{6}{|l|}{ Gender } \\
\hline Male & $2.6(1.3-3.7)$ & $2.548(0.761-8.525)$ & 0.129 & - & \\
\hline Female & $9.7(0.9-18.4)^{\mathrm{a}}$ & Reference & & & \\
\hline \multicolumn{6}{|l|}{ ECOG PS } \\
\hline 2 & 3.6 (ND-ND) & $1.174(0.159-8.671)$ & 0.875 & - & \\
\hline $0-1$ & $3.0(2.3-3.6)$ & Reference & & & \\
\hline \multicolumn{6}{|l|}{ Hepatitis serology } \\
\hline HBsAg-positive & $2.5(1.8-3.3)$ & $1.440(0.440-4.713)$ & 0.547 & $1.139(0.328-3.957)$ & 0.837 \\
\hline Other & $3(0.8-5.1)$ & Reference & & Reference & \\
\hline \multicolumn{6}{|l|}{ Child-Pugh score } \\
\hline 6 & $1.6(0.0-4.3)$ & $0.905(0.275-2.975)$ & 0.870 & - & \\
\hline 5 & $3.0(2.3-3.6)$ & Reference & & & \\
\hline \multicolumn{6}{|l|}{ Histological grade } \\
\hline Poor & $2.5(1.1-3.8)$ & $1.564(0.804-3.041)$ & 0.187 & $1.005(0.440-2.293)$ & 0.991 \\
\hline Well/moderate & $3.4(1.9-4.8)$ & Reference & & Reference & \\
\hline \multicolumn{6}{|l|}{ BCLC stage } \\
\hline $\mathrm{C}$ & $3.0(2.3-3.6)$ & $1.752(0.526-5.838)$ & 0.361 & - & \\
\hline B & 0.9 (ND-ND) & NA & & & \\
\hline A & $1.6(0.0-5.2)$ & Reference & & & \\
\hline \multicolumn{6}{|l|}{ Tumor size, cm } \\
\hline$\geq 10$ & $3.2(2.7-3.6)$ & $0.644(0.322-1.286)$ & 0.212 & $0.449(0.220-0.917)$ & $0.028^{\mathrm{b}}$ \\
\hline$<10$ & $1.8(0.6-3.0)$ & Reference & & Reference & \\
\hline \multicolumn{6}{|l|}{ Tumor nodules } \\
\hline Multiple & $3.0(1.0-4.9)$ & $0.936(0.451-1.944)$ & 0.859 & $0.644(0.289-1.437)$ & 0.282 \\
\hline Single & $2.5(1.7-3.4)$ & Reference & & Reference & \\
\hline \multicolumn{6}{|l|}{ AFP, ng/ml } \\
\hline$\geq 400$ & $2.5(1.9-3.2)$ & $1.180(0.620-2.248)$ & 0.614 & $1.049(0.511-2.153)$ & 0.896 \\
\hline$<400$ & $3.0(0.0 .2-5.8)$ & Reference & & Reference & \\
\hline \multicolumn{6}{|l|}{ Previous treatment } \\
\hline Yes & $9.2(0.0-23.7)$ & $0.204(0.059-0.703)$ & $0.012^{\mathrm{b}}$ & $0.299(0.073-1.221)$ & 0.093 \\
\hline No & $2.5(1.2-3.9)$ & Reference & & Reference & \\
\hline \multicolumn{6}{|c|}{ Anti-virus treatment } \\
\hline Yes & $3.1(2.7-3.5)$ & $0.596(0.300-1.183)$ & 0.139 & $0.851(0.402-1.800)$ & 0.673 \\
\hline No & $2.4(0.6-4.1)$ & Reference & & Reference & \\
\hline
\end{tabular}

${ }^{a}$ Mean $(95 \% \mathrm{CI}) .{ }^{\mathrm{b}} \mathrm{P}<0.05$ indicates significant association. DFS, disease-free survival; HR, hazard ratio; $95 \% \mathrm{CI}, 95 \%$ confidence interval; ECOG, Eastern Cooperative Oncology Group Performance Status; HBsAg, hepatitis B virus surface antigen; BCLC, Barcelona Clinic Liver Cancer Stage; AFP, $\alpha$-fetoprotein; ND, not derived (due to small sample size); NA, not assessed (due to only one subject in BCLC stage B).

with $400 \mathrm{mg}$ sorafenib once daily (42). Furthermore, in a case-controlled study of 39 patients that experienced HCC recurrence following liver transplantation, the median survival time from recurrence was significantly improved with sorafenib as compared with BSC, and sorafenib was identified as the only factor associated with survival by multivariate analysis (48). The effect of sorafenib on recurrence has also been observed in animal studies. For example, Feng et al (49) demonstrated 
that sorafenib suppresses postsurgical recurrence and metastasis via enhancing the sensitivity of HCC cells to sorafenib in an orthotopic mouse model. In a study by Wang et al (50), sorafenib suppressed metastatic recurrence following resection in nude mice. By contrast, a recent phase III randomized, double-blind, placebo-controlled study of sorafenib therapy following resection or ablation with curative intent in 1,114 patients revealed no differences in recurrence-free survival, time to recurrence or overall survival between patients receiving sorafenib or placebo (51). It is possible that differences in disease severity (early-stage versus high-risk advanced disease) between the studies could account for the varying outcomes.

In a previous study, 44 Italian patients with $\mathrm{HCC}$ and established cirrhosis were treated with sorafenib for 16 weeks. In these patients, ECOG PS, extrahepatic spread, macrovascular invasion, and AFP and ALP levels at admission were identified as independent predictors of overall survival (52). In another study of 110 patients with advanced HCC that were treated with sorafenib in Germany, ascites, macrovascular invasion and BCLC stage D were independently associated with overall survival (53). Furthermore, the use of nucleoside analogues was associated with a lower risk of HCC recurrence (36). By contrast, the use of antiviral therapy was the same in both groups in the present study. Although factors associated with overall survival were not assessable for analysis in the present study due to the length of the follow-up period, histological grade, BCLC stage, tumor size, nodule number and high serum AFP levels were not associated with DFS.

Despite the fact that the present results differ from those reported by previous studies $(36,52,53)$, the present data are still solid due to the following reasons. Firstly, in the current study, only patients with a high risk of recurrence were included. Patients were defined as being at a high risk of recurrence if they had one of the following intraoperative findings: i) Tumors involving a major branch of the portal or hepatic vein (i.e., PVTT); ii) tumors with direct invasion of adjacent organs; and iii) tumor ruptures prior to or during resection. The above risks may become the main factors that decide the prognosis. Secondly, histological grade, BCLC stage, tumor size, nodule number and high serum AFP levels were not associated with DFS in the present study.

The patients in the current study were selected on the basis of their being at a high risk for recurrence, including those with PVTT, adjacent organ involvement and tumor rupture. In addition to surgical resection, patients with PVTT are typically treated with a portal vein stents, TACE, radiotherapy, ${ }^{125}$ I seed implantation, PEI and laser ablation (18). Although TACE appears to have potential for providing a survival benefit for HCC patients with PVTT, with a median PFS of 3.6-5.1 months $(54,55)$, the deteriorating liver function caused by TACE limits its application $(56,57)$. By contrast, hepatic resection may produce superior survival benefits for HCC patients with PVTT, with a 1-year overall survival rate of $34.4-42.0 \%$ (58-61), and radiotherapy may have superior local effects in these patients $(62,63)$. The prognosis of HCC patients with PVTT is dismal. Therapy strategies for such patients, including TACE, had been compared in previous studies. Peng et al reported that hepatic resection, compared with TACE, provided survival benefits for patients with resectable HCC with PVTT, particularly for those with type I or II PVTT (58). Chen et al noticed that liver resection with thrombectomy, compared with liver resection without thrombectomy, yielded better outcomes in HCC patients with PVTT confined to the first or second branch of the main portal vein compared with those with PVTT extending into the main portal vein (59). Le Treut et al observed that liver resection in HCC patients with PVTT, compared with patients without PVTT, could provide significant survival with comparable morbidity in selected cases, that is, tumor thrombus located in the portal vein only and expected complete resection of the lesions (60). Shi et al demonstrated that liver resection with portal thrombectomy for HCC cases with PVTT, compared with resection without portal thrombectomy, is justified in selected patients with PVTT located in the segmental or sectoral branches of the portal vein (61). Zhang et al suggested that percutaneous transhepatic portal vein stenting (PTPVS)-TACE combined with three-dimensional conformal radiotherapy (3-DCRT), compared with PTPVS-TACE without 3-DCRT, is possibly an effective treatment modality for HCC with PVTT (63).Kim et al noticed that radiotherapy induced a $45.8 \%$ objective response rate for PVTT in patients with HCC, and considered that radiotherapy may be a treatment option for PVTT in patients with HCC (62).

In the present study, the median DFS in patients with PVTT who underwent resection was 5.2 months $(95 \%$ CI, 2.0-8.4 months) in the sorafenib group and 1.8 months (95\% CI, 0-3.7 months) in the BSC group ( $\mathrm{P}=0.002)$. However, considering that only $5-40 \%$ of patients with HCC are receptive to resection (3), further studies should be performed to examine the impact of sorafenib treatment in combination with TACE, radiotherapy, PEI and laser ablation.

In the present study, no patient experienced an adverse event that resulted in discontinuation of sorafenib therapy. This is consistent with a previous study by Wang et al (25), in which only grades 1 and 2 drug-related adverse events were observed with sorafenib therapy, as well as other studies that observed no serious adverse events associated with sorafenib therapy in patients with advanced HCC $(48,64)$. By contrast, grade 4 liver-related adverse events have been reported for Child-Pugh class B patients (65), with poorer outcomes observed in class B versus class A advanced HCC patients following sorafenib therapy (66). All the patients in the present study were classified as Child-Pugh class A, which may explain why sorafenib was well-tolerated.

Access to sorafenib can significantly alter the survival of patients with advanced HCC. This was demonstrated in a recent study from the UK, in which the median overall survival time in advanced HCC patients with access to sorafenib was 9.5 months compared with the 4.1 months observed in patients for whom sorafenib was unavailable due to a lack of approval by a local health funding body (67). This applies to patients in Asian-Pacific countries, where sorafenib is currently not widely available.

The major limitations of the present study include the relatively small number of patients, the short-term follow-up period and its retrospective nature. Another limitation is that only HCC patients with a high risk of recurrence were included; therefore, the role of sorafenib in patients with a low risk of recurrence remains to be elucidated. In addition, due to the short follow-up period, only 9 mortalities were observed and the median overall survival time could not be 
determined. Additionally, as sorafenib is not widely available to Asian-Pacific patients due to differences in clinical practice, it is likely that the group of patients receiving sorafenib financed the treatment themselves. Therefore, the sorafenib group may have had a higher socioeconomic status and may have received a more aggressive treatment protocol compared with the BSC group, representing a study bias. Furthermore, a significantly higher proportion of patients in the sorafenib group received previous treatment compared with those in the BSC group, which may have affected the results.

In conclusion, sorafenib therapy following resection may prolong DFS in patients with advanced HCC. However, further multi-center studies with larger cohorts and longer follow-up times are required to confirm the results of the current study.

\section{Acknowledgements}

The present study was supported by grants from the National Natural Science Foundation of China (nos. 81372571 and 81101863), Guangdong Department of Science and Technology Translational Medicine Center (no. 2011A080300002), and the Innovative PhD Project of Sun Yat-Sen University.

\section{References}

1. Raza A and Sood GK: Hepatocellular carcinoma review: Current treatment and evidence-based medicine. World J Gastroenterol 20: 4115-4127, 2014

2. Ferlay J, Shin HR, Bray F, Forman D, Mathers C and Parkin DM: Estimates of worldwide burden of cancer in 2008: GLOBOCAN 2008. Int J Cancer 127: 2893-2917, 2010.

3. Bruix J and Sherman M: American Association for the Study of Liver Diseases: Management of hepatocellular carcinoma: An update. Hepatology 53: 1020-1022, 2011.

4. European Association For The Study Of The Liver; European Organisation For Research And Treatment Of Cancer: EASL-EORTC clinical practice guidelines: Management of hepatocellular carcinoma. J Hepatol 56: 908-943, 2012.

5. Forner A, Llovet JM and Bruix J: Hepatocellular carcinoma Lancet 379: 1245-1255, 2012.

6. Schwartz JD, Schwartz M, Mandeli J and Sung M: Neoadjuvant and adjuvant therapy for resectable hepatocellular carcinoma: Review of the randomised clinical trials. Lancet Oncol 3: 593-603, 2002.

7. Lai EC, Lo CM, Fan ST, Liu CL and Wong J: Postoperative adjuvant chemotherapy after curative resection of hepatocellular carcinoma: A randomized controlled trial. Arch Surg 133: 183-188, 1998

8. Izumi R, Shimizu K, Iyobe T, Ii T, Yagi M, Matsui O, Nonomura A and Miyazaki I: Postoperative adjuvant hepatic arterial infusion of Lipiodol containing anticancer drugs in patients with hepatocellular carcinoma. Hepatology 20: 295-301, 1994.

9. Miyake Y, Takaki A, Iwasaki Y and Yamamoto K: Meta-analysis: Interferon-alpha prevents the recurrence after curative treatment of hepatitis C virus-related hepatocellular carcinoma. J Viral Hepat 17: 287-292, 2010.

10. Lo CM, Liu CL, Chan SC, Lam CM, Poon RT, Ng IO, Fan ST and Wong J: A randomized, controlled trial of postoperative adjuvant interferon therapy after resection of hepatocellular carcinoma. Ann Surg 245: 831-842, 2007.

11. Shen YC, Hsu C, Chen LT, Cheng CC, Hu FC and Cheng AL: Adjuvant interferon therapy after curative therapy for hepatocellular carcinoma (HCC): A meta-regression approach. J Hepatol 52: 889-894, 2010

12. Zhong Y,Liu B, Deng M and Xu R: Adjuvant systemic drug therapy and recurrence of hepatocellular carcinoma following curative resection. Drug Discov Ther 7: 164-166, 2013.

13. Minagawa M and Makuuchi M: Treatment of hepatocellular carcinoma accompanied by portal vein tumor thrombus. World $\mathrm{J}$ Gastroenterol 12: 7561-7567, 2006.

14. TakizawaD,Kakizaki S,SoharaN,SatoK, Takagi H,Arai H,Katakai K, Kojima A, Matsuzaki Y and Mori M: Hepatocellular carcinoma with portal vein tumor thrombosis: Clinical characteristics, prognosis and patient survival analysis. Dig Dis Sci 52: 3290-3295, 2007.
15. Okuda K, Ohtsuki T, Obata H, Tomimatsu M, Okazaki N, Hasegawa H, Nakajima Y and Ohnishi K: Natural history of hepatocellular carcinoma and prognosis in relation to treatment. Study of 850 patients. Cancer 56: 918-928, 1985.

16. Yeung YP, Lo CM, Liu CL, Wong BC, Fan ST and Wong J: Natural history of untreated nonsurgical hepatocellular carcinoma. Am J Gastroenterol 100: 1995-2004, 2005.

17. Lee HS, Kim JS, Choi IJ, Chung JW, Park JH and Kim CY: The safety and efficacy of transcatheter arterial chemoembolization in the treatment of patients with hepatocellular carcinoma and main portal vein obstruction. A prospective controlled study. Cancer 79: 2087-2094, 1997.

18. Chuan-Xing L, Xu H, Bao-Shan H, Yong L, Pei-Jian S, Xian-Yi Y, Xiao-Ning L and Li-Gong L: Efficacy of therapy for hepatocellular carcinoma with portal vein tumor thrombus: Chemoembolization and stent combined with iodine-125 seed. Cancer Biol Ther 12: 865-871, 2011.

19. Wilhelm SM, Carter C, Tang L, Wilkie D, McNabola A, Rong H, Chen C, Zhang X, Vincent P, McHugh M, et al: BAY 43-9006 exhibits broad spectrum oral antitumor activity and targets the $\mathrm{RAF} / \mathrm{MEK} / \mathrm{ERK}$ pathway and receptor tyrosine kinases involved in tumor progression and angiogenesis. Cancer Res 64: 7099-7109, 2004.

20. Wilhelm S, Carter C, Lynch M, Lowinger T, Dumas J, Smith RA, Schwartz B, Simantov R and Kelley S: Discovery and development of sorafenib: A multikinase inhibitor for treating cancer. Nat Rev Drug Discov 5: 835-844, 2006.

21. Wilhelm SM, Adnane L, Newell P, Villanueva A, Llovet JM and Lynch M: Preclinical overview of sorafenib, a multikinase inhibitor that targets both Raf and VEGF and PDGF receptor tyrosine kinase signaling. Mol Cancer Ther 7: 3129-3140, 2008.

22. Chang YS, Adnane J, Trail PA, Levy J, Henderson A, Xue D, Bortolon E, Ichetovkin M, Chen C, McNabola A, et al: Sorafenib (BAY 43-9006) inhibits tumor growth and vascularization and induces tumor apoptosis and hypoxia in RCC xenograft models. Cancer Chemother Pharmacol 59: 561-574, 2007.

23. Llovet JM, Ricci S, Mazzaferro V, Hilgard P, Gane E, Blanc JF, de Oliveira AC, Santoro A, Raoul JL, Forner A, et al: Sorafenib in advanced hepatocellular carcinoma. N Engl J Med 359: 378-390, 2008.

24. Cheng AL, Kang YK, Chen Z, Tsao CJ, Qin S, Kim JS, Luo R,Feng J, Ye S, Yang TS, et al: Efficacy and safety of sorafenib in patients in the Asia-Pacific region with advanced hepatocellular carcinoma: A phase III randomised, double-blind, placebo-controlled trial. Lancet Oncol 10: 25-34, 2009.

25. Wang SN, Chuang SC and Lee KT: Efficacy of sorafenib as adjuvant therapy to prevent early recurrence of hepatocellular carcinoma after curative surgery: A pilot study. Hepatol Res 44: 523-531, 2014.

26. Oken MM, Creech RH, Tormey DC, Horton J, Davis TE, McFadden ET and Carbone PP: Toxicity and response criteria of the Eastern Cooperative Oncology Group. Am J Clin Oncol 5: 649-655, 1982.

27. Bruix J, Sherman M, Llovet JM, Beaugrand M, Lencioni R, Burroughs AK, Christensen E, Pagliaro L, Colombo M and Rodés J; EASL Panel of Experts on HCC: Clinical management of hepatocellular carcinoma. Conclusions of the Barcelona-2000 EASL conference. European Association for the Study of the Liver. J Hepatol 35: 421-430, 2001.

28. Salerno F, Merli M, Cazzaniga M, Valeriano V, Rossi P, Lovaria A, Meregaglia D, Nicolini A, Lubatti L and Riggio O: MELD score is better than Child-Pugh score in predicting 3-month survival of patients undergoing transjugular intrahepatic portosystemic shunt. J Hepatol 36: 494-500, 2002.

29. Kleihues $P$ and Sobin LH: World Health Organization classification of tumors. Cancer 88: 2887, 2000.

30. Wanless IR; International Working Party: Terminology of nodular hepatocellular lesions. Hepatology 22: 983-993, 1995.

31. Sobin LH and Fleming ID: TNM Classification of Malignant Tumors, fifth edition (1997). Union Internationale Contre le Cancer and the American Joint Committee on Cancer. Cancer 80: 1803-1804, 1997.

32. Luo J, Peng ZW, Guo RP, Zhang YQ, Li JQ, Chen MS and Shi M: Hepatic resection versus transarterial lipiodol chemoembolization as the initial treatment for large, multiple and resectable hepatocellular carcinomas: A prospective nonrandomized analysis. Radiology 259: 286-295, 2011

33. Trotti A, Colevas AD, Setser A, Rusch V, Jaques D, Budach V, Langer C, Murphy B, Cumberlin R, Coleman CN and Rubin P: CTCAE v3.0: Development of a comprehensive grading system for the adverse effects of cancer treatment. Semin Radiat Oncol 13: 176-181, 2003. 
34. Therasse P, Arbuck SG, Eisenhauer EA, Wanders J, Kaplan RS, Rubinstein L, Verweij J, Van Glabbeke M, van Oosterom AT, Christian MC and Gwyther SG: New guidelines to evaluate the response to treatment in solid tumors. European Organization for Research and Treatment of Cancer, National Cancer Institute of the United States, National Cancer Institute of Canada. J Natl Cancer Inst 92: 205-216, 2000.

35. Imamura H, Matsuyama Y, Tanaka E, Ohkubo T, Hasegawa K, Miyagawa S, Sugawara Y, Minagawa M, Takayama T, Kawasaki S and Makuuchi M: Risk factors contributing to early and late phase intrahepatic recurrence of hepatocellular carcinoma after hepatectomy. J Hepatol 38: 200-207, 2003.

36. Wu CY, Chen YJ, Ho HJ, Hsu YC, Kuo KN, Wu MS and Lin JT: Association between nucleoside analogues and risk of hepatitis B virus-related hepatocellular carcinoma recurrence following liver resection. JAMA 308: 1906-1914, 2012.

37. Zhong JH, Ke Y, Gong WF, Xiang BD, Ma L, Ye XP, Peng T, Xie GS and Li LQ: Hepatic resection associated with good survival for selected patients with intermediate and advanced-stage hepatocellular carcinoma. Ann Surg 260. 329-340, 2014

38. Shindoh J, Hasegawa K, Inoue Y, Ishizawa T, Nagata R, Aoki T, Sakamoto Y, Sugawara Y, Makuuchi M and Kokudo N: Risk factors of post-operative recurrence and adequate surgical approach to improve long-term outcomes of hepatocellular carcinoma. HPB (Oxford) 15: 31-39, 2013

39. Tanaka K, Shimada M and Kudo M: Characteristics of long-term survivors following sorafenib treatment for advanced hepatocellular carcinoma: Report of a workshop at the 50th annual meeting of the liver cancer study group of Japan. Oncology 87 (Suppl 1): 104-109, 2014.

40. Nagano H, Miyamoto A, Wada H, Ota H, Marubashi S, Takeda Y, Dono K, Umeshita K, Sakon M and Monden M: Interferon-alpha and 5-fluorouracil combination therapy after palliative hepatic resection in patients with advanced hepatocellular carcinoma, portal venous tumor thrombus in the major trunk and multiple nodules. Cancer 110: 2493-2501, 2007.

41. Dollinger MM, Lautenschlaeger C, Lesske J, Tannapfel A, Wagner AD, Schoppmeyer K, Nehls O, Welker MW, Wiest R and Fleig WE; AIO Hepatobiliary Study Group: Thymostimulin versus placebo for palliative treatment of locally advanced or metastasised hepatocellular carcinoma: A phase III clinical trial. BMC Cancer 10: $457,2010$.

42. Shiozawa K, Watanabe M, Ikehara T, Matsukiyo Y, Kogame M, Kanayama M, Matsui T, Kikuchi Y, Ishii K, Igarashi Y and Sumino Y: Sustained complete response of hepatocellular carcinoma with portal vein tumor thrombus following discontinuation of sorafenib: A case report. Oncol Lett 7: 50-52, 2014.

43. Wang Z, Zhou J, Fan J, Qiu SJ, Yu Y, Huang XW and Tang ZY: Effect of rapamycin alone and in combination with sorafenib in an orthotopic model of human hepatocellular carcinoma. Clin Cancer Res 14: 5124-5130, 2008

44. Richly H, Schultheis B, Adamietz IA, Kupsch P, Grubert M, Hilger RA, Ludwig M, Brendel E, Christensen O and Strumberg D: Combination of sorafenib and doxorubicin in patients with advanced hepatocellular carcinoma: Results from a phase I extension trial. Eur J Cancer 45: 579-587, 2009.

45. Chung YH, Han G, Yoon JH, Yang J, Wang J, Shao GL, Kim BI, Lee TY and Chao Y: Interim analysis of START: Study in Asia of the combination of TACE (transcatheter arterial chemoembolization) with sorafenib in patients with hepatocellular carcinoma trial. Int J Cancer 132: 2448-2458, 2013.

46. Barbier L, Muscari F, Le Guellec S, Pariente A, Otal P and Suc B: Liver resection after downstaging hepatocellular carcinoma with sorafenib. Int J Hepatol 2011: 791013, 2011.

47. Azad NS, Posadas EM, Kwitkowski VE, Steinberg SM, Jain L, Annunziata CM, Minasian L, Sarosy G, Kotz HL, Premkumar A, et al: Combination targeted therapy with sorafenib and bevacizumab results in enhanced toxicity and antitumor activity. J Clin Oncol 26 : 3709-3714, 2008

48. Sposito C, Mariani L, Germini A, Flores Reyes M, Bongini M, Grossi G, Bhoori S and Mazzaferro V: Comparative efficacy of sorafenib versus best supportive care in recurrent hepatocellular carcinoma after liver transplantation: A case-control study. J Hepatol 59: 59-66, 2013.

49. Feng YX, Wang T, Deng YZ, Yang P, Li JJ, Guan DX, Yao F, Zhu YQ, Qin Y, Wang H, et al: Sorafenib suppresses postsurgical recurrence and metastasis of hepatocellular carcinoma in an orthotopic mouse model. Hepatology 53: 483-492, 2011.
50. Wang Z, Hu J, Qiu SJ, Huang XW, Dai Z, Tan CJ, Zhou J and Fan J: An investigation of the effect of sorafenib on tumor growth and recurrence after liver cancer resection in nude mice independent of phosphorylated extracellular signal-regulated kinase levels. Expert Opin Investig Drugs 20: 1039-1045, 2011.

51. Bruix J, Takayama T, Mazzaferro V, et al: STORM: A phase III randomized, double-blind, placebo-controlled trial of adjuvant sorafenib after resection or ablation to prevent recurrence of hepatocellular carcinoma (HCC). J Clin Oncol 32 (suppl 5): Abtract 4006, 2014

52. Inghilesi AL, Gallori D, Antonuzzo L, Forte P, Tomcikova D, Arena U, Colagrande S, Pradella S, Fani B, Gianni E, et al: Predictors of survival in patients with established cirrhosis and hepatocellular carcinoma treated with sorafenib. World J Gastroenterol 20: 786-794, 2014

53. Wörns MA, Koch S, Niederle IM, Marquardt JU, Nguyen-Tat M, Gamstätter T, Schuchmann M, Schulze-Bergkamen H, Galle PR and Weinmann A: The impact of patient and tumour baseline characteristics on the overall survival of patients with advanced hepatocellular carcinoma treated with sorafenib. Dig Liver Dis 45: 408-413, 2013.

54. Ikeda M, Okusaka T, Furuse J, Mitsunaga S, Ueno H, Yamaura H, Inaba Y, Takeuchi Y, Satake M and Arai Y: A multi-institutional phase II trial of hepatic arterial infusion chemotherapy with cisplatin for advanced hepatocellular carcinoma with portal vein tumor thrombosis. Cancer Chemother Pharmacol 72: 463-470, 2013.

55. Kalva SP, Pectasides M, Liu R, Rachamreddy N, Surakanti S, Yeddula K, Ganguli S, Wicky S, Blaszkowsky LS and Zhu AX: Safety and effectiveness of chemoembolization with drug-eluting beads for advanced-stage hepatocellular carcinoma. Cardiovasc Intervent Radiol 37: 381-387, 2014.

56. Fan J, Wu ZQ, Tang ZY, Zhou J, Qiu SJ, Ma ZC, Zhou XD and Ye SL: Multimodality treatment in hepatocellular carcinoma patients with tumor thrombi in portal vein. World J Gastroenterol 7: 28-32, 2001.

57. Tazawa J, Maeda M, Sakai Y, Yamane M, Ohbayashi H, Kakinuma S, Miyasaka Y, Nagayama K, Enomoto N and Sato C: Radiation therapy in combination with transcatheter arterial chemoembolization for hepatocellular carcinoma with extensive portal vein involvement. J Gastroenterol Hepatol 16: 660-665, 2001.

58. Peng ZW, Guo RP, Zhang YJ, Lin XJ, Chen MS and Lau WY: Hepatic resection versus transcatheter arterial chemoembolization for the treatment of hepatocellular carcinoma with portal vein tumor thrombus. Cancer 118: 4725-4736, 2012.

59. Chen XP, Qiu FZ, Wu ZD, Zhang ZW, Huang ZY, Chen YF and Zhang BX: Effects of location and extension of portal vein tumor thrombus on long-term outcomes of surgical treatment for hepatocellular carcinoma. Ann Surg Oncol 13: 940-946, 2006.

60. Le Treut YP, Hardwigsen J, Ananian P, Saisse J, Gregoire E, Richa H and Campan P: Resection of hepatocellular carcinoma with tumor thrombus in the major vasculature. A European case-control series. J Gastrointest Surg 10: 855-862, 2006.

61. Shi J, Lai EC, Li N, Guo WX, Xue J, Lau WY, Wu MC and Cheng SQ: Surgical treatment of hepatocellular carcinoma with portal vein tumor thrombus. Ann Surg Oncol 17: 2073-2080, 2010.

62. Kim DY, Park W, Lim DH, Lee JH, Yoo BC, Paik SW, Kho KC, Kim TH, Ahn YC and Huh SJ: Three-dimensional conformal radiotherapy for portal vein thrombosis of hepatocellular carcinoma. Cancer 103: 2419-2426, 2005.

63. Zhang XB, Wang JH, Yan ZP, Qian S, Du SS and Zeng ZC: Hepatocellular carcinoma with main portal vein tumor thrombus: Treatment with 3-dimensional conformal radiotherapy after portal vein stenting and transarterial chemoembolization. Cancer 115 : 1245-1252, 2009

64. Berk V, Kaplan MA, Tonyali O, Buyukberber S, Balakan O, Ozkan M, Demirci U, Ozturk T, Bilici A, Tastekin D, et al: Efficiency and side effects of sorafenib therapy for advanced hepatocellular carcinoma: A retrospective study by the anatolian society of medical oncology. Asian Pac J Cancer Prev 14: 7367-7369, 2013.

65. Zugazagoitia J, Manzano A, Sastre J, Ladero JM, Puente J and Díaz-Rubio E: Sorafenib for non-selected patient population with advanced hepatocellular carcinoma: Efficacy and safety data according to liver function. Clin Transl Oncol 15: 146-153, 2013.

66. Pressiani T, Boni C, Rimassa L, Labianca R, Fagiuoli S, Salvagni S, Ferrari D, Cortesi E, Porta C, Mucciarini C, et al: Sorafenib in patients with Child-Pugh class A and B advanced hepatocellular carcinoma: A prospective feasibility analysis. Ann Oncol 24: 406-411, 2013.

67. Palmer DH, Hussain SA, Smith AJ, Hargreaves S, Ma YT, Hull D, Johnson PJ and Ross PJ: Sorafenib for advanced hepatocellular carcinoma (HCC): Impact of rationing in the United Kingdom. Br J Cancer 109: 888-890, 2013. 